\title{
Sudden Heart Pathology-a New Research Hipotesys
}

\author{
Luisetto $\mathrm{M}^{1}$, Luca Cabianca ${ }^{2}$, Farhan Ahmad Khan $^{3}$ and Ghulam Rasool Mashori ${ }^{4}$ \\ ${ }^{1}$ European Specialist in Lab Medicine, Applied Pharmacologist, Italy \\ ${ }^{2}$ Biomedical Laboratory, Italy \\ ${ }^{3}$ Professor and Head Department of Pharmacology AIMSRC, India \\ ${ }^{4}$ Peoples University of Medical and Health Sciences for Woman, Pakistan
}

Submission: September 28, 2017; Published: October 20, 2017

*Corresponding author: Luisetto M, European Specialist in lab Medicine, Applied Pharmacologist, Italy 29121, Email: maurolu65@gmail.com

Keywords: Cardiology; Heart disease; Diagnostic systems

\section{Introduction}

We can see that heart is usually studied using many diagnostic strategies and under different Mechanism as functions, electric activity, receptorial, imaging, instrumental test, genetic profile, exercise tests, biopsy and so on. But what we can see is that until today in not possible to prevent some unexpected death. So we can think that perhaps we need more diagnostic test to right consider this aspect. Can we use innovative methods to introduce more useful systems? In ischemic condition some test can help to detect the residual heart capacity but can we test in the same way the heart biochemical-metabolic status or pharmacological profile? In a recent case we have see that in a transplant heart procedure was used an organ by a patient death Due to cerebral damage after a heart attack and after few days the transplanted has exits due by heart pathology. (Fact observed in advanced healthcare systems). It was reported that coronarography was normal in donor. Can we think new methods to early detect this kind of condition? Can we have a ranking useful to differentiate normal and abnormal patients? How react a normal organ in Para-physiological condition (alteration of electrolytes, acidbasebalace, oxygen level and so on).

In example as we easily see in other pathologies as diabetes or other endocrine disease patient are investigated in normal situation and after metabolic charge to correctly have a more complete information useful in clinical therapy. (The same in example to verify bioavability in vivo in single transplanted patient under some immunodepressant drugs are investigated with a kinetic ematic assay, or in neurology setting to correctly evaluate some anti epileptic pharmacological strategy Therapeutic drug monitoring is usually done to evaluate the single patient hepatic status- citocrome).

\section{From biomedical literature we can see}

Buxton [1] write: "The guidelines are focused primarily on the appropriate use of implantable defibrillator. The bulk of the guidelines have very little basis in the underlying pathophysiology responsible for sudden cardiac death (SCD) in CHD patients" [1].

Shen et al. [2] showed that "The risk of SCD has changed over time among patients with symptomatic HF and reduced ejection fraction with sequential introduction of drugs as ACE inhibitors, angiotensin-receptor blockers, beta-blockers drugs, and mineralcorticoid-receptor antagonists" [2].

According Demosthenes Katritsis G et al. [3] "CAD is the most common cause of SCD, being responsible $80 \%$ of cases; cardiosympathies and genetic channel-patsies account for most of the remainder. The incidence of SCD-related atherosclerotic CAD is 0.7 per 100,000 person-years in 18 -35 year olds, increasing to 13.7 per 100,000 in those $>35$ years of age. Valve disease and dilated or arrhythmo-genic cardio-sympathy are more common" [3].

"Following IMA there is increased risk of SCD during the first months due to tacky-arrhythmias or other heart complications: reinfarction or myocardial rupture, and myocardial scar predisposes to mono morphic ventricular tachycardia (VT). Although most 
patients with a cardiac arrest have demonstrable CAD, however, less than half seem to have suffered an IMA. Only 38\% of cardiac arrest survivors develop evidence of IMA. The most common causes of non-ischemic SCD are currently cardio-sympathy related to obesity alcoholism and fibrotic cardio-sympathy.

In patients with preserved ejection fraction in the Cardiac Arrest Survivors with Preserved Ejection Fraction Registry, etiological diagnosis was possible in approximately half of cardiac arrest survivors. A resuscitated cardiac arrest victim, preferably with documentation of VF, in whom known cardiac, respiratory, metabolic and toxicological etiologies have been excluded through clinical evaluation is considered to have idiopathic VF. Several ionchannel and gene-coding mutations have been associated with idiopathic VF. Genetic testing diagnoses an inherited arrhythmia (genetic channelopathy) in up to $29 \%$ of families where a relative has died due to SCD. Several studies have also demonstrated a familial predisposition to SCD that may or may not be related to genetic channelopathies.

Coronary spasm is also a cause of cardiac arrest, particularly in male smokers with minimal or no pre-existing CAD. Mitral valve prolapsed in female patients with ECG depolarization abnormalities and frequent complex ventricular ectopic has also been associated with out-of-hospital cardiac arrest. An association between air pollution (fine particulate matter with an aerodynamic diameter $<2.5 \mu \mathrm{m}$ and ozone) and out-of-hospital cardiac arrest has recently been demonstrated. There is a circadian variation in SCD. The peak incidence of SCD occurs between 6am and noon (and is blunted by beta-blockers), with a smaller peak occurring in the late afternoon for out-of-hospital VF arrests. The incidence is highest on Mondays.

In the young $(<35$ years), the most common cause of SCD is arrhythmia, mostly in the context of an apparently normal heart. The most common causes of SCD are congenital abnormalities in those aged 0-13 years, primary arrhythmia in the 14-24 years age group and CAD in those $>25$ years. In 5-20\% of cases no significant cardiac abnormality is found at autopsy. In a recent Danish registry report on individuals aged $<50$ years, sudden death was caused by non cardiac diseases, such as pulmonary embolism, meningitis and cerebrovascular bleeding, in $28 \%$ of cases.

In sports-related sudden death in the population a clear diagnosis is made in $<25 \%$ of cases but the cause is usually an acute coronary syndrome (75\%). In professional athletes, a diagnosis is usually made in up to $65 \%$ of cases and hypertrophic cardiomyopathy (HCM) is considered the main cause at least in the United States, followed by arrhythmogenic right ventricular cardiomyopathy (ARVC, especially in the Veneto region of Italy), congenital coronary anomalies, genetic channelopathies, myocarditis, Wolff-Parkinson-White syndrome and Marfan syndrome, with blunt trauma, commotiocordis and heat stroke being less frequent causes. There is evidence, however, that HCM may not be the major cause of SCD in athletes. Autopsies in deceased NCAA athletes most often reveal a structurally normal heart (25\%), followed by coronary artery anomalies (11\%), myocarditis (9\%), ARVC (5\%) and aortic dissection (5\%) with HCM only demonstrated in $8 \%$ of individuals.

Findings from the Race Associated Cardiac Arrest Event Registry (RACER) indicate that marathons and half-marathons are associated with a low overall risk of cardiac arrest or sudden death $(1: 100,000)$ with deaths most commonly attributable to HCM $(26 \%)$ or atherosclerotic coronary disease $(16 \%)$. Some of these cardiac arrests might however have been provoked by heat stroke. CAD is the predominant cause of SCD in older athletes. Vigorous exertion can trigger cardiac arrest or SCD, especially in untrained persons, but habitual vigorous exercise diminishes the risk of sudden death during vigorous exertion. Most studies have found inverse associations between regular physical activity and SCD" [3] so we have see that various etiology are related to this pathology: Ventricular tachiaritmia, VF, bradiarithmia, electro mechanical dissociation, systole, pulse less electrical activity, channel pathologies y and other conditions. But in about 20\% cases not associated to abnormality found at autopsy, and that a Vigorous exertion can trigger a cardiac arrest or SCD, especially in untrained subjects [3].

\section{Discussion and Conclusion}

Related to our consideration we can think a new method in heart disease staging strategy. New tests that can make possible to stress cardiac metabolism in normal, lowland high working conditions or in para-phisio-pathological conditions but in local place (heart situation and not in plasma in example). We think that this new methods can be useful in much heart disease and condition to prevent some events. (Heart attacks, ischemic disease, atria, heart failure, transplants, sports and so on). Every bio-medical discipline has specific diagnostic discipline, but it can be useful to translate the various diagnostic system strategies from a discipline to other: this make possible to observe phenomena with.

\section{A different point of view}

In the young common the most common causes of SCD IS arithmia mostly in apparently normal heart [3]. The difference in incidence SCD-atherosclerotic related between young patient and non young that we have seen is a fundamental objective data.

The same also the relationship within sudden vigorous exertion untrained subjects (also in young) seems to show an inadeguatemethabolic response that must be adequately investigate. As we have see in the citied references sudden death must be deeply studied in order to better clarify the pathologic cause. [1-3] especially in young people. To prevent this kind of disease we think can be useful introduce new diagnostic strategy to verify in stressing conditions the local metabolic heart performance. 


\section{Clarifications}

This paper has not any diagnostic or therapy intent only to produce research hipotesys under Stricltly Ethical principle in use.

\section{References}

1. Buxton AE (2017) Sudden death in ischemic heart disease-2017. Int J Cardiol 237: 64-66.
2. Shen L, Jhund PS, Petrie MC, Claggett BL, Barlera S, et al. (2017) Declining Risk of Sudden Death in Heart Failure. N Engl J Med 377(1): 41-51.

3. Katritsis G, Gersh BJ, Camm J (2016) A Clinical Perspective on Sudden Cardiac Death Demosthenes. Arrhythm Electrophysiol Rev 5(3): 177182.

\section{Your next submission with Juniper Publishers will reach you the below assets}

- Quality Editorial service

- Swift Peer Review

- Reprints availability

- E-prints Service

- Manuscript Podcast for convenient understanding

- Global attainment for your research

- Manuscript accessibility in different formats ( Pdf, E-pub, Full Text, Audio)

- Unceasing customer service

Track the below URL for one-step submission https://juniperpublishers.com/online-submission.php 